\title{
LA-UR- $00-3592$
}

\section{Solid-State NMR studies for DC 745:}

\section{April-May 2000 \\ Tom Stephens - ESA-WMM Andrea Labouriau-CST-18}

Introduction: Powles et al. ${ }^{1}$ reported in 1961 that polydimethyl siloxane melts exhibit a transverse decay of nuclear spin magnetization $\left(T_{2}\right)$ that is nonexponential. This observation was interpreted in terms of the proton NMR signal from the melt having characteristics of a broad line. Since then, similar findings were obtained for other polymer melts too. Accordingly to Powles et al. this peculiar proton line shape was the result of an intramolecular direct dipole-dipole interaction between a pair of protons. They also suggested that this dipolar interaction was weak because the dipolar interaction was motionally averaged since the orientation-dependent local dipolar field is modulated by molecular dynamics. In sum, the consequences and the origins of nuclear spin correlations in viscous polymer melts were recognized almost 4 decades ago. In the 1970 s, Cohen-Addad ${ }^{2,3}$ suggested that these weak proton dipolar interactions could be used to characterize polymer melts and networks. In this work, we have used some of these ideas to probe the effects of thermal treatments on the proton spin-spin relaxation times for DC745.

Experimental Section: DC 745u was obtained from Dow Corning. After the curing process, the sample was postcured for 1 hour at $150 \mathrm{C}$ and 8 hours at $250 \mathrm{C}$. According to LANL notes obtained for this sample, this postcure cycle was developed to avoid the possibility of byproducts or low molecular weight residuals exuding from the part when it is confined in assembly. Thus, the sample studied by NMR has already been cured and postcured. Aging effects were probed by heating the sample in air at $250 \mathrm{C}$ for a total of 59.5 hours. $\mathrm{T}_{2}$ experiments were performed after the sample has been heated during varied times:2, 3.5, 18.5, 41.5 and 59.5 hours. Also, at the NMR lab, the 59.5 hours-aged sample and the unaged sample were hydrated (at about $100 \%$ humidity, room temperature) for a total of three weeks. $T_{2}$ experiments were performed for these two samples as well. 


\section{DISCLAIMER}

This report was prepared as an account of work sponsored by an agency of the United States Government. Neither the United States Government nor any agency thereof, nor any of their employees, make any warranty, express or implied, or assumes any legal liability or responsibility for the accuracy, completeness, or usefulness of any information, apparatus, product, or process disclosed, or represents that its use would not infringe privately owned rights. Reference herein to any specific commercial product, process, or service by trade name, trademark, manufacturer, or otherwise does not necessarily constitute or imply its endorsement, recommendation, or favoring by the United States Government or any agency thereof. The views and opinions of authors expressed herein do not necessarily state or reflect those of the United States Government or any agency thereof. 


\section{DISCLAIMER}

Portions of this document may be illegible in electronic image products. Images are produced from the best available original document. 
Solid-state NMR experiments were performed at TA-48, with a Varian Unity 400 spectrometer operating at $400 \mathrm{MHz}$ for ${ }^{1} \mathrm{H}$. Furthermore, ${ }^{29} \mathrm{Si}$ and ${ }^{13} \mathrm{C}$ MAS NMR (magic angle spinning) experiments were also performed for DC745.

Results: Figure 1 shows the transverse magnetization decays obtained for DC745 as a function of the total time that this sample has been heated at $250 \mathrm{C}$. As we can see, after 2 hours the sample became stiffer (faster relaxation decay). The next point ( 3.5 hours), is very similar to the first one ( 2 hours). After that, the next three points (18.5, 41.5 and 59.5 hours) show exactly the same relaxation decays but faster than the former ones. Figure 2 shows the transverse magnetization decays obtained for the aged and unaged samples that have been hydrated. These curves are compared to their counterparts ones. Next, the chemical composition of DC745 was obtained using ${ }^{29} \mathrm{Si}$ and ${ }^{13} \mathrm{C}$ MAS NMR. The results are listed in tables 1 and 2.

Discussion: In order to understand the $T_{2}$ data, we have to consider the filler in some detail. LANL data on DC745 indicates that the filler used is fumed silica. Fumed silica is obtained by burning silica tetrachloride in a flame or by high-temperature hydrolysis of silicon tetrachloride. The silica surface contains three kinds of silanols: isolated, geminal, and vicinal. ${ }^{3}$ The surface also contains exposed siloxane bonds (Si-O-Si). The silanols are considered strong adsorption sites, while siloxane sites are usually considered hydrophobic. Silanols presented on the surface can be thermally removed at high temperatures with formation of the siloxane bond and release of water molecules. It has been shown ${ }^{4}$ that at $190 \pm 10 \mathrm{C}$ essentially all physically adsorbed water is removed. Dehydration and dehydroxylation of silica were shown to be very heterogeneous processes. According to Zhuravlev ${ }^{4}$, the majority of physically adsorbed water can be easily removed from the surface at $25 \mathrm{C}$ in vacuum. But, a monolayer or less of water is retained on the surface up to ca. 200C. Further heating (200-400C) results in dehydroxylation of bonded silanols (the number of isolated silanols may slightly increase). Above $400 \mathrm{C}$ the number of isolated silanols decreases.

Based on the discussion above, the influence of the thermal treatment on the silica surface needs to be considered. It is reasonable to infer that the changes in the transverse magnetization decay as the ones reported in Figure 1 are probably related to the reledise of adsorbed water from the surface of the filler. Heating the sample at $250 \mathrm{C}$ in air, slowly 
removes the strongly held monolayer of water on the silica surface. This gives rise to a higher number of free adsorption sites on the surface of the filler for the polymer chains to interact with. Figure 1 shows that after the sample have been heated at $250 \mathrm{C}$, the magnetization decay becomes faster. Faster is the magnetization decay more solid-like is the sample. Or in other words, we infer that the aged sample becomes stiffer than the unaged one due to a stronger interaction with the filler surface. In order to test this idea, cross-polarization experiments would be an invaluable tool.

As for the aged sample that has been hydrated for 3 weeks, the magnetization decay is essentially the same as for the sample without any further hydration (see Figure 2). This result seems to indicate that once the polymer chains have been adsorbed on the surface of the filler, water molecules can not displace them. On in other words, this effect seems to be irreversible under these experimental conditions. This same result is obtained for the hydrated unaged sample, which shows the same relaxation decay as for the non-hydrated one.

Overall, this study suggests that any thermal treatment may have a very strong influence on the silica surface chemistry, and consequenty on the properties of the polymer/filler system. We suggest cross-polarization experiments to verify the supposition that the aged sample becomes stiffer due to an increase of the surfacepolymer interaction.

\section{References:}

1. Powles, J. G.; Hartland, A.; Kail, J. A. E. J. Polym. Sci. 55, 361, 1961.

2. Cohen-Addad, J. Chem. Phys. 60, 2440, 1974.

It is worth mentioning that I did my $\mathrm{Ph} . \mathrm{D}$ with Cohen-Adjad hi Grenoble, where I applied these same techniques to study the dynamics of high molecula weigh polymex See for instance, NMR investigations in Highy Entangle $\bar{f}$ folybutadene Chains.

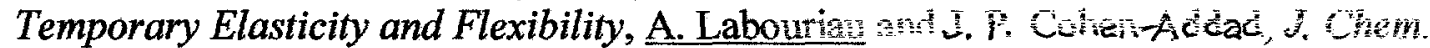

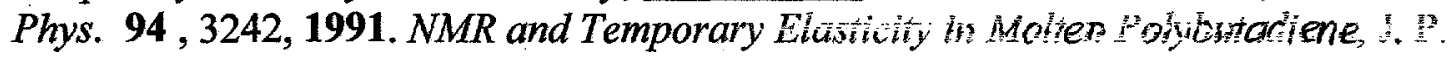
Cohen-Addad and A. Labouriau, $J$. Chem. $P h_{y y} .93,2011,1090$.

3. Nawrocki, J. J. Chromatogr. A, 779, 29, 1997.

4. Zhuravlev, L. T., Pure Appl. Chem. 61, 1969, 1999. 
Table 1. Chemical composition calculated from ${ }^{29} \mathrm{Si}$ MAS NMR for DC745:

\begin{tabular}{|c|c|c|c|}
\hline Si species & $\begin{array}{c}\text { Chemical } \\
\text { shift } \delta(p p m)\end{array}$ & $\begin{array}{c}\% \text { of total } \\
{ }^{29} \mathrm{Si} \mathrm{NMR} \\
\text { signal } \\
\text { DC745 } \\
\text { new }\end{array}$ & $\begin{array}{c}\text { \% of total } \\
{ }^{29} \text { Si NMR } \\
\text { signal } \\
\text { DC745 } \\
\text { aged }^{*}\end{array}$ \\
\hline $\begin{array}{c}\mathrm{Me} \\
\text {-O-Si-O- } \\
1 \\
\mathrm{Me} \\
\end{array}$ & -22.1 & $75 \%$ & $75 \%$ \\
\hline $\begin{array}{c}\mathrm{O} \\
\text {-O-Si-O- } \\
1 \\
\mathrm{Me} \\
\end{array}$ & $\begin{array}{c}-66.8 \\
(\sim-66)\end{array}$ & $\begin{array}{c}\text { Small } \\
\text { amounts }\end{array}$ & $\begin{array}{c}\text { Small } \\
\text { amounts }\end{array}$ \\
\hline $\begin{array}{c}\text { Ph or vinyl } \\
\text {-O-Si-O- } \\
1 \\
\mathrm{Me} \\
\end{array}$ & -33.9 & About $6 \%$ & About $6 \%$ \\
\hline Filler & $\begin{array}{c}-110 \text { broad peak } \\
-107.4 \text { very sharp } \\
\text { peak (quartz) }\end{array}$ & $\begin{array}{c}\text { About } 15 \% \\
\text { fumed silica and } \\
3 \% \text { quartz }\end{array}$ & $\begin{array}{c}\text { About } 15 \% \\
\text { fumed silica and } \\
3 \% \text { quartz }\end{array}$ \\
\hline
\end{tabular}

- *The aged sample was heated at $250 \mathrm{C}$ for a total time of 59.5 hours in air. 
Table 2. Chemical composition calculated from ${ }^{13} \mathrm{C}$ MAS NMR for unaged DC745:

\begin{tabular}{|c|c|}
\hline Carbon species & \% of total ${ }^{13} \mathrm{C}$ NMR signal \\
\hline $\begin{array}{c}\text { CH3 } \\
- \text { O-Si-O- }\end{array}$ & $90 \%$ \\
\hline Ph groups & About $7 \%$ \\
\hline Vinyl groups & About $2 \%$ \\
\hline
\end{tabular}




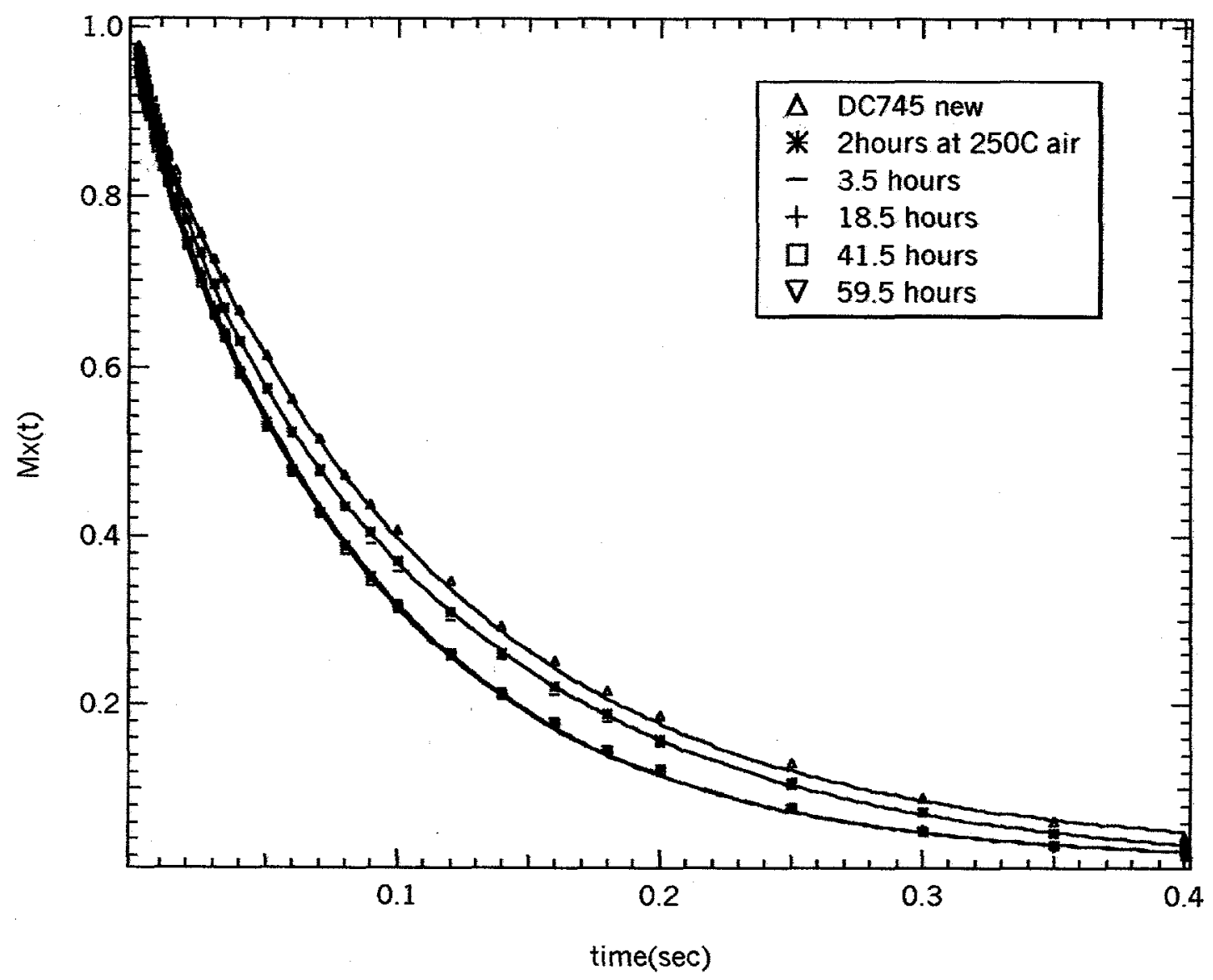

Figure 1 


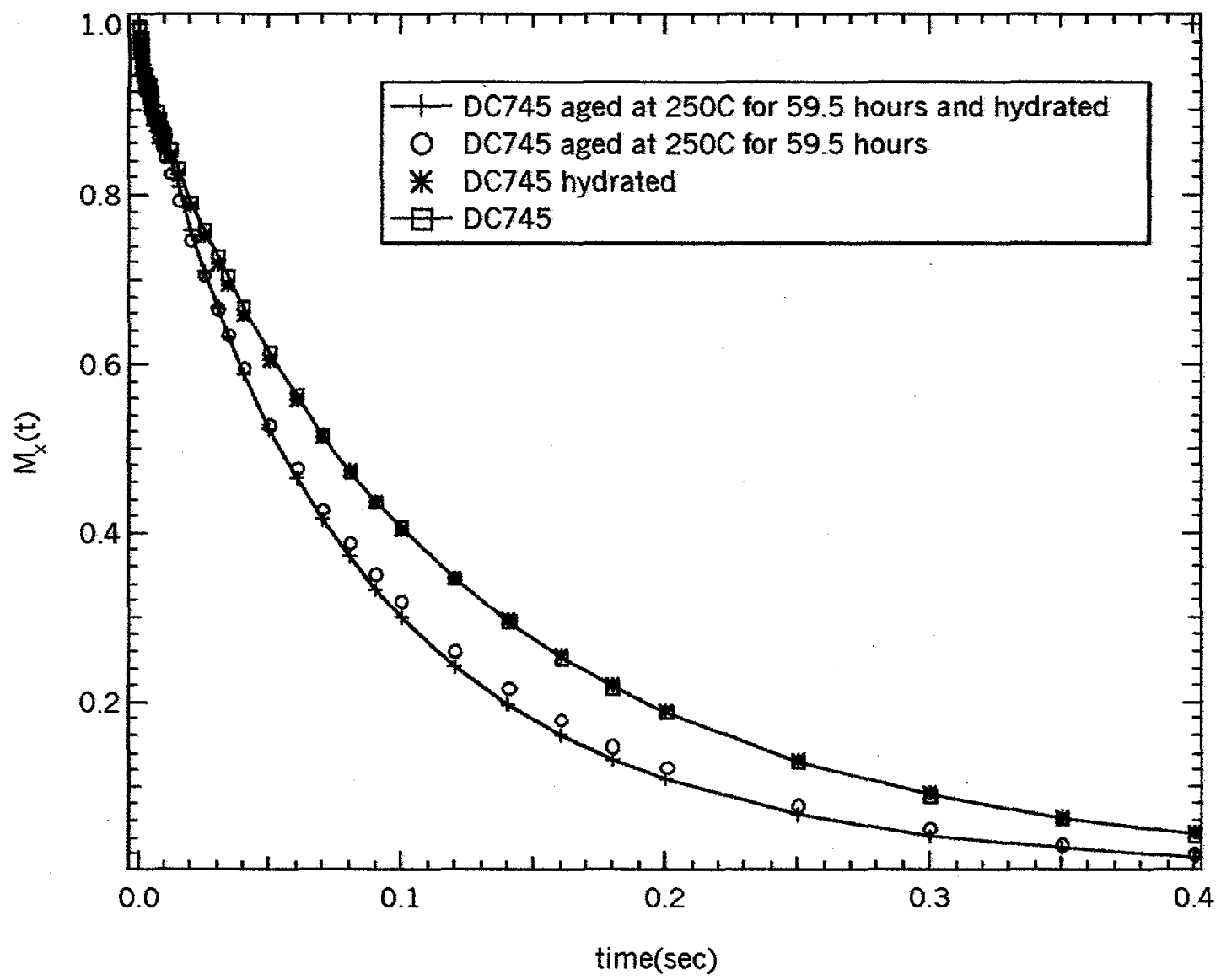

Figure 2. 